\title{
$\widehat{A}$ Madridge
}

madridge Journal of Internal and Emergency Medicine

\author{
Interconnecting Scientific World
}

Research Article

Open Access

\section{Experience of Vasoactive Therapy from Esophageal Variceal Bleeding in Patients with Hepatic Cirrhosis and Syndrome of Portal Hypertension}

\author{
Mikhail M Vinokurov*, Gavril G Sobakin, Vladimir G Ammosov, Innokenty K Semenov, Anton A Yakovlev, \\ Vasily P Ignatiev, Sardana V Leontieva, Vladimir V Popov, Gavril S Osipov, and Lyudmila M Vinokurova \\ Department of Faculty Surgery, Urology, Oncology and Otorhinolaryngology, North-Eastern Federal University, M.K. Ammosov, Yakutsk, Russia
}

\section{Article Info}

*Corresponding author:
Mikhail M Vinokurov
Professor \& Head
Department of Faculty Surgery, Urology,
Oncology and Otorhinolaryngology
North-Eastern Federal University
Russia
E-mail: mmv_mi@rambler.ru

Received: April 25, 2019

Accepted: May 24, 2019

Published: May 31, 2019

Citation: Vinokurov MM, Sobakin GG, Ammosov VG, Semenov IK, Yakovlev AA, Ignatiev VP, Leontieva SV, VV Popov, Osipov GS and Vinokurova LM. Experience of Vasoactive Therapy from Esophageal Variceal Bleeding in Patients with Hepatic Cirrhosis and Syndrome of Portal Hypertension. Madridge J Intern Emerg Med. 2019; 3(2): 125-127.

doi: $10.18689 / \mathrm{mjiem}-1000129$

Copyright: $\odot 2019$ The Author(s). This work is licensed under a Creative Commons Attribution 4.0 International License, which permits unrestricted use, distribution, and reproduction in any medium, provided the original work is properly cited.

Published by Madridge Publishers

\begin{abstract}
To evaluate the effectiveness of vasoactive therapy with synthetic somatostatin analogues at acute esophageal variceal bleeding in patients with hepatic cirrhosis with portal hypertension syndrome. A retrospective analysis of the results of a comprehensive treatment of patients with cirrhosis and portal hypertension syndrome was done. The study is based on a retrospective analysis of the results of a comprehensive treatment of 57 patients who were on treatment at the emergency surgical department of the Republican Hospital №2 - the Center for Emergency Medical Care of the Republic of Sakha (Yakutia) in the period from 2015 to 2017.

The presented clinical experience of the use of synthetic somatostatin analogues in complex therapy at acute esophageal variceal bleeding allows recommending their wide use in the practice of urgent surgical clinics.
\end{abstract}

Keywords: Hepatic Cirrhosis; Portal Hypertension; Esophageal Variceal Bleeding; Vasoactive Therapy.

\section{Introduction}

It is well known that among a number of numerous causes of gastrointestinalbleeding, esophageal varicose vein dilatation (EVVD) is at least $5-10 \%$ [1]. In most patients with hepatic cirrhosis $(\mathrm{HC})$, a portal hypertension syndrome (PGS) occurs, which in more than $60-70 \%$ of cases is complicated by the development of gastrointestinal bleeding [2]. According to Shercinger AG [3], mortality even after the first episode of bleeding is more than $30 \%$, and in $50-70 \%$ of cases, it's rebleeding. Treatment of complications of PGS, especially hemorrhage from EVVD, remains to this day an urgent problem of urgent gastroenterology due to high mortality and a large number of their rebleeding [3]. A key role in the development of esophageal varicose vein dilatation and bleeding is played by an increase in the portocaval pressure gradient. Risk factors are the degree of varicose enlargement, the presence of «red markers» and the severity of hepatic dysfunction [4]. The risk of developing bleeding from the EVVD in patients with $\mathrm{HC}$ within the first year is $10-15 \%$ and reaches $30 \%$ by the end of the second year of the disease [5]. If bleeding is stopped without the use of endoscopic or surgical methods, bleeding recurrence occurs in $50-70 \%$ of patients and in $80-90 \%$ in the case of a twoyear follow-up $[5,6]$. Currently, combined treatment with vasoactive drugs and endoscopic methods is recommended [7]. 


\section{Materials and Methods}

The presented work is based on a retrospective analysis of the results of complex treatment of 57 patients with $\mathrm{HC}$ and PGS who were on treatment in the emergency surgical department of the Republican Hospital №2 - Center for Emergency Medical Care of the Republic of Sakha (Yakutia) in the period from 2015 to 2017 . The average age of the patients was 45,1 $\pm 6,5$ years, with men being $38(66,7 \%)$, women - 19 $(33,3 \%)$. The diagnosis of HP and PGS is verified on the basis of a multilevel complex examination. All patients were taken to the clinic by an ambulance carriage with a clinical picture of bleeding from the EVVD and subsequently hospitalized in the intensive care unit (ICU). The volume of intensive care was determined in accordance with the recommendations of the international consensus Baveno VI (2015) (Italy) [8]. The main areas of intensive care were: the replenishment of circulating blood, the use of hemostatic and vasoactive drugs, antibiotics (for the treatment and prevention of spontaneous bacterial ascites-peritonitis), hepatoprotectors, anticoagulants. Synthetic somatostatin analogs were used as vasoactive agents (Somatostatin, Octreotide). Endoscopic examination was performed with GIF Type 2 T 160 gastrofibroscope firm «Olympus» (Japan). In interpreting the endoscopic picture, they were guided by the recommendations of the Japanese scientific society on the study of portal hypertension [9]. The cumulative degree of esophageal and gastric dilatation was established according to the modified criteria of K-J Paquet [10].

The statistical processing of the material was carried out using the StatPlus 2007 statistical program for the Microsoft Office 2007 operating system, as well as the IBM.SPSS. Statistiks.v22 software package. When estimating the whole population, the mean values $(\mu)$ and the standard deviation $(\sigma)$ were calculated, the reliability of differences (p) was determined by the Newman-Keils criterion.

\section{Results and Discussion}

To achieve the purpose of this study, patients were divided into two groups. The first (control) group included 23 $(40,4 \%)$ of the observed patients who had only the SengstakenBlakemore probe installed to stop bleeding from the EVVD.
The second (main) group comprised 34 (59,6\%) patients, who along with the installation of the Sengstaken-Blakemore probe in complex intensive therapy used synthetic somatostatin analogues (Table 1).

Table 1. Demographic, clinical-nosological characteristics of research groups

\begin{tabular}{|c|c|c|c|c|c|c|}
\hline \multirow{3}{*}{ Test subject } & \multicolumn{6}{|c|}{ Number of patients } \\
\hline & \multicolumn{2}{|c|}{$\begin{array}{c}1 \text { (control) } \\
\text { group }(n=23)\end{array}$} & \multicolumn{2}{|c|}{$\begin{array}{c}2 \text { (main) group } \\
(\mathrm{n}=34)\end{array}$} & \multicolumn{2}{|c|}{ Total $(n=57)$} \\
\hline & Abs. & $M \pm \varepsilon$ & Abs. & $M \pm \varepsilon$ & Abs. & $\mathrm{p}$ \\
\hline Age, years & \multicolumn{2}{|c|}{$48,1 \pm 11,8$} & \multicolumn{2}{|c|}{$43,2 \pm 12,7$} & \multicolumn{2}{|c|}{$45,1 \pm 6,5$} \\
\hline Men's & 14 & $36,8 \pm 2,4$ & 24 & $63,2 \pm 1,7$ & 38 & $P<0,05$ \\
\hline Women & 9 & $47,4 \pm 2,5$ & 10 & $52,6 \pm 1,8$ & 19 & $P<0,05$ \\
\hline Viral hepatitis B & 4 & $36,4 \pm 1,3$ & 7 & $63,6 \pm 1,1$ & 11 & $P<0,05$ \\
\hline Viral hepatitis C & 4 & $31,6 \pm 2,1$ & 13 & $68,4 \pm 1,5$ & 19 & $P<0,05$ \\
\hline Mixed-hepatitis B+D & 2 & $66,7 \pm 2,7$ & 1 & $33,3 \pm 2,1$ & 3 & $P<0,05$ \\
\hline Mixed-hepatitis $B+C+D$ & 1 & $50,0 \pm 2,6$ & 1 & $50,0 \pm 1,9$ & 2 & $P<0,05$ \\
\hline Alcoholic HC & 7 & $38,9 \pm 2,1$ & 11 & $61,1 \pm 1,5$ & 18 & $P<0,05$ \\
\hline Cryptogenic HC & 3 & $75,0 \pm 2,5$ & 1 & $25,0 \pm 1,8$ & 4 & $P<0,05$ \\
\hline \multicolumn{7}{|l|}{ EVVD } \\
\hline II degree & 1 & $33,3 \pm 1,7$ & 2 & $66,7 \pm 1,2$ & 3 & $P<0,05$ \\
\hline III degree & 14 & $41,2 \pm 1,3$ & 20 & $58,1 \pm 11,8$ & 34 & $P<0,05$ \\
\hline IV degree & 8 & $40,0 \pm 1,6$ & 12 & $60,0 \pm 1,9$ & 20 & $P<0,05$ \\
\hline \multicolumn{7}{|l|}{ Child-Pughcreiteria } \\
\hline Class A & 2 & $40,0 \pm 1,8$ & 3 & $60,0 \pm 1,1$ & 5 & $P<0,05$ \\
\hline Class A & 11 & $36,7 \pm 2,3$ & 19 & $63,3 \pm 2,1$ & 30 & $P<0,05$ \\
\hline Class A & 10 & $48,5 \pm 1,4$ & 12 & $54,5 \pm 1,6$ & 22 & $\mathrm{P}<0,05$ \\
\hline
\end{tabular}

*Reliability of differences of the I group in the relation to II $p<0,05$.

As in Kotiv BN study [5], in order to evaluate the effect of vasoactive therapy on hemodynamic, a comparative analysis of mid arterial pressure, heart rate, cardiac output, and the main dopplerographic indices of portal blood flow at the time of admission was made and 30 and 90 minutes after the introduction of the synthetic somatostatin analogue (Table 2). BPmid, mm Hg. - mid arterial pressure, HR - heart rate, Vmid. vp.cm/s - time averaged speed over the portal vein, VFvp, $\mathrm{ml} /$ min - volumetric speed of the portal vein, RI - hepatic artery resistance index.

Table 2. Parameters of central and regional portal hemodynamics

\begin{tabular}{|c|c|c|c|c|c|c|}
\hline \multirow[b]{2}{*}{ Index } & \multicolumn{3}{|c|}{ 1(Control) group } & \multicolumn{3}{|c|}{ 2(main)group } \\
\hline & $\begin{array}{l}\text { At the time of } \\
\text { admission }\end{array}$ & $\begin{array}{l}\text { After } 30 \\
\text { minutes }\end{array}$ & $\begin{array}{l}\text { After } 90 \\
\text { minutes }\end{array}$ & $\begin{array}{l}\text { At the time of } \\
\text { admission }\end{array}$ & $\begin{array}{l}\text { After } 30 \\
\text { minutes }\end{array}$ & $\begin{array}{l}\text { After } 90 \\
\text { minutes }\end{array}$ \\
\hline BPmid, mm Hg. & $130,4 \pm 4,5$ & $110,2 \pm 7,6$ & $115,8 \pm 8,9$ & $107,2 \pm 7,1$ & $98,1 \pm 7,1$ & $101,4 \pm 6,5$ \\
\hline $\mathrm{HR}$ & $107,3 \pm 8,1$ & $99,3 \pm 7,1$ & $90,6 \pm 4,6$ & $110,8 \pm 8,3$ & $84,2 \pm 6,5$ & $86,7 \pm 3,7$ \\
\hline Cardiac outputl/min & $8,6 \pm 4,3$ & $7,4 \pm 3,4$ & $7,3 \pm 4,4$ & $9,6 \pm 5,1$ & $8,2 \pm 3,3$ & $8,5 \pm 3,8$ \\
\hline Vmid.vp.cm/s & $20,9 \pm 6,6$ & $19,7 \pm 3,1$ & $15,4 \pm k 3,0$ & $21,9 \pm 5,2$ & $17,6 \pm 3,9$ & $19,1 \pm 4,5$ \\
\hline VFvp, $\mathrm{ml} / \mathrm{min}$ & $760,4 \pm 271,2$ & $668,1 \pm 284,3$ & $578,5 \pm 234,6$ & $734,5 \pm 256,1$ & $621,7 \pm 201,3$ & $699,9 \pm 275,2$ \\
\hline $\mathrm{RI}$ & $0,82 \pm 0,18$ & $0,74 \pm 0,15$ & $0,65 \pm 0,12$ & $0,86 \pm 0,22$ & $0,62 \pm 0,11$ & $0,76 \pm 0,17$ \\
\hline
\end{tabular}

*Reilability of diffrnces of the I group in relation to II $p<0,05$

BPmid, mm Hg. - mid arterial, HR - heart rate, Vmid.vp.cm/s - time averaged speed over the portal vein, VFvp, ml-min volumetric speed of portal vein, $\mathrm{Rl}$ - hepatic artery resistance index

The study found that the introduction of synthetic somatostatin analogs was accompanied by a significant decrease in both linear and volume flow rate of the portal vein from $21,9 \pm 5,2$ to $17,6 \pm 3,9 \mathrm{~cm} / \mathrm{s}$ and $734,5 \pm 621,7$ to $621,7 \pm 201,3 \mathrm{ml} / \mathrm{min}$, respectively. This effect was observed after 90 minutes from the administration of the drug. On average, the portal blood flow speed decreased by $20,1 \pm 3,7 \%(p<0,05)$, and the volume flow 
of blood decreased by $17,4 \pm 2,8 \%(p<0,05)$. The index of resistance of the hepatic artery also decreased somewhat, but no significant differences were found in the groups $(p<0,05)$.

It should also be noted that the introduction of synthetic somatostatin analogs was accompanied by changes in the parameters of central hemodynamics. There was a decrease in the mean arterial pressure and heart rate, a decrease in cardiac output.

Esophageal-gastric bleeding of portal genesis is the most frequent and life threatening complication of chronic diffuse liver diseases [5]. Over the past decade, due to the widespread introduction of endoscopic methods for the prevention and control of bleeding from EVVD and modern vasoactive drugs, the mortality from bleeding from EVVD has decreased from 40-60\% to $10-15 \%$ [11]. However, all the same authors note that $20-30 \%$ of patients have profuse, hard to control bleeding, and early rebleeding develop in every 5 patients [12]. At present, it is generally accepted that complex pharmacotherapy contributes to the achievement of hemostasis in a significant number of patients [13]. The most justified is the prescription of drugs, whose action is aimed at reducing portal pressure and reducing blood flow to the EVVD. Studies have shown that with the development of bleeding vasoactive drugs should be introduced as early as possible, and their use is continued to prevent recurrence of bleeding within 5-7 days $[14,15]$. The results of the study showed that the combined use of the Sengstaken Blakemore probe against the background of a 24-hour intravenous injection of synthetic somatostatin analogues for bleeding from the EVVD made it possible to achieve hemostasis in $94,3 \%$ of the observations. Early recurrence of bleeding from the EVVD in the first 5-7 days after stopping bleeding against the background of the administration of drugs was noted in only $4(11,8 \%)$ patients, another $2(5,9 \%)$ of our patients had repeated episodes of hemorrhage at the 10th and 14th day of inpatient treatment. In the case of patients of the control group, in the complex treatment in which only the installation of the SengstakenBlakemore obturator was used to stop bleeding, it was not much more than $77,6 \%$ of cases that the hemostasis was achieved. Early recurrence of bleeding in the first 5-7 days was noted in $5(21,7 \%)$ patients and in $3(13,0 \%)$, episodes of bleeding were fixed on the 9th and 12th day of treatment. In this case, the common mortality in the main group was $10.7 \%$, and in the control group - $36.8 \%$.

\section{Conclusion}

Thus, the following can be drawn that, in addition to the widespread introduction of endoscopic and endovascular methods of stopping bleeding from the EVVD in clinical practice, pharmacotherapy is an integral part of the treatment. Priority direction of therapy with vasoactive drugs should be considered the earliest inclusion in the intensive care complex of synthetic somatostatin analogues. The data obtained by us allow us to consider synthetic analogs of somatostatin, as the drugs of choice for bleeding from EVVD.

\section{References}

1. Merli M, Nicolini G, Angeloni S, et al. Incidence and natural history of small esophageal varices in cirrhotic patients. J Hepatol. 2003; 38(3): 266-272.

2. Rusin VI. Immediate results of treatment of esophageal variceal bleeding in patients with B-class liver cirrhosis. News of Surgery. 2013; 21(1): 36-45.

3. Shercinger AG. Treatment of esophageal and stomach variceal bleeding. Annals of Surgical Hepatology. 2013; 3: 110-129.

4. Argonz J, Kravetz D, Suarez A, et al. Variceal band ligation and variceal band ligation plus sclerotherapy in the prevention of recurrent variceal bleeding in cirrhotic patients: a randomized, prospective and controlled trial. J Gastrointest Endosc. 2000; 51(5): 157-163.

5. Kotiv BN. The use of terlipressin at esophageal variceal bleeding in patients with liver cirrhosis with the syndrome of portal hypertension. Russian Journal of Gastroenterology, Hepatology, Coloproctology. 2013; 5: 57-64.

6. de Franchis R. Updating consensus in portal hypertension: report of the Baveno III Consensus Workshop on definitions, methodology and therapeutic strategies in portal hypertension. J Hepatol. 2000; 33(5): 846852.

7. de Franchis R, Baveno V Faculty. Revising consensus in portal hypertension: report of the Baveno $V$ Consensus Workshop on methodology of diagnosis and therapy in portal hypertension. J Hepatol. 2010; 53(4): 762768. doi: 10.1016/j.jhep.2010.06.004

8. Lyalyukova EA. Tactics of management of patients with portal hypertension syndrome in the presence of liver cirrhosis (based on Baveno VI Consensus, 2015). Attending Physician. 2017; 8: 42.

9. Filin AV. Endoscopic diagnostics, primary and secondary prevention of esophageal and stomach variceal bleeding. Practical Medicine. 2008; 2 (26): $37-40$.

10. Paquet K-J. Endoscopic paravariceal injection sclerotherapy of the esophagus - indications, technique, complications, results of period of nearly 14 years. Gastrointest Endosc. 1993; 29: 310-315.

11. Garcia-Pagan JC, Reverter E, Abraldes JG, Bosch J. Acute variceal bleeding. Semin RespirCritCare Med.2012;33(1):46-54. doi:10.1055/s-0032-1301734

12. Seo YS, Park SY, Kim MY, et al. Lack of difference among terlipressin, somatostatin, and octreotide in the control of acute gastro-esophageal variceal hemorrhage. Hepatology. 2014; 60(3): 954-963. doi: 10.1002/ hep. 27006

13. Krag A, Bendtsen F, Mortensen C, Henriksen JH, Møller S. Effects of a single terlipressin administration on cardiac function and perfusion in cirrhosis. Eur J Gastroenterol Hepatol. 2010; 22(9): 1085-1092. doi: 10.1097/ MEG.0b013e32833a4822

14. Lo $G H$, Perng DS, Chang $C Y$, et al. Controlled trial of ligation plus vasoconstrictor versus proton pump inhibitor in the control of acute esophageal variceal bleeding. J Gastroenterol Hepatol. 2013; 28(4): 684689. doi: $10.1111 /$ jgh. 12107

15. Wells $\mathrm{M}, \mathrm{Chande} \mathrm{N}$, Adams $\mathrm{P}$, et al. Meta-analysis: vasoactive medications for the management of acute variceal bleeds. Aliment Pharmacol Ther. 2012; 35(11): 1267-1278. doi: 10.1111/j.1365-2036.2012.05088.x 